\title{
Effect of the flavonoid hesperidin on glucose and fructose transport, sucrase activity and glycaemic response to orange juice in a crossover trial on healthy volunteers
}

\author{
Asimina Kerimi ${ }^{1}$, Julia S. Gauer ${ }^{1}$, Susannah Crabbe ${ }^{1}$, Jia W. Cheah ${ }^{1}$, Jay Lau ${ }^{1}$, Rosa Walsh ${ }^{2}$, \\ Paul F. Cancalon ${ }^{2}$ and Gary Williamson ${ }^{1,3}$ \\ ${ }^{1}$ School of Food Science and Nutrition, University of Leeds, Leeds LS2 9JT, UK \\ ${ }^{2}$ Florida Department of Citrus, 700 Experiment Station Road, Lake Alfred, FL 33850, USA \\ ${ }^{3}$ Department of Nutrition, Dietetics and Food, School of Clinical Sciences at Monash Health, Faculty of Medicine, Nursing and \\ Health Sciences, Monash University, Notting Hill BASE facility, 264 Ferntree Gully Road, Notting Hill, VIC 3168, Australia
}

(Submitted 11 July 2018 - Final revision received 12 December 2018 - Accepted 2 January 2019 - First published online 23 January 2019)

\section{Abstract}

Although polyphenols inhibit glucose absorption and transport in vitro, it is uncertain whether this activity is sufficient to attenuate glycaemic response in vivo. We examined this using orange juice, which contains high levels of hesperidin. We first used a combination of $i n$ vitro assays to evaluate the potential effect of hesperidin and other orange juice components on intestinal sugar absorption and then tested whether this translated to an effect in healthy volunteers. Hesperidin attenuated transfer of ${ }^{14} \mathrm{C}$-labelled glucose across differentiated Caco-2/TC7 cell monolayers. The involvement of the sugar transporter GLUT2 was demonstrated by experiments carried out in the absence of Na to exclude the contribution of sodium-glucose linked transporter 1 and further explored by the use of Xenopus laevis oocytes expressing human GLUT2 or GLUT5. Fructose transport was also affected by hesperidin partly by inhibition of GLUT5, while hesperidin, even at high concentration, did not inhibit rat intestinal sucrase activity. We conducted three separate crossover interventions, each on ten healthy volunteers using orange juice with different amounts of added hesperidin and water. The biggest difference in postprandial blood glucose between orange juice and control, containing equivalent amounts of glucose, fructose, sucrose, citric acid and ascorbate, was when the juice was diluted $\left(\Delta C_{\mathrm{max}}=-\right.$ $0.5 \mathrm{~mm}, P=0.0146$ ). The effect was less pronounced when the juice was given at regular strength. Our data indicate that hesperidin can modulate postprandial glycaemic response of orange juice by partial inhibition of intestinal GLUT, but this depends on sugar and hesperidin concentrations.

\section{Key words: Postprandial responses: Transporters: Citrus fruits: Sucrose: Flavonoids: Intestine}

According to a meta-analysis of human intervention studies, diets that consist of low glycaemic index foods have significant health benefits when compared to diets high in rapidly absorbable sugars ${ }^{(1)}$, while high glycaemic index carbohydrates in developed nations have contributed to the epidemics of obesity and cardiometabolic disease ${ }^{(2)}$. The glycaemic index of foods is affected by many factors, but certain natural compounds present may reduce the rate of sugar digestion and absorption and hence modify the glycaemic index, even in foods with comparable amounts of carbohydrate. In fact, this notion was first suggested for polyphenols more than 30 years ago $^{(3)}$, but has received more attention only recently, owing to the increased threat of developing diabetes in a high proportion of the global population ${ }^{(4)}$. The appearance of postprandial glucose in the blood is accompanied by mobilisation of hormones such as insulin which assist extra-hepatic tissues in taking up the excess glucose. Previous research has suggested that the glycaemic response can be attenuated by several polyphenol-rich foods, such as coffee ${ }^{(5)}$, green tea ${ }^{(6)}$, berries ${ }^{(7)}$ and pomegranate juice ${ }^{(8)}$. The mechanism may be partly through inhibition of digestive enzymes such as $\alpha$-amylase, as clinically exemplified by acarbose ${ }^{(9)}$, but also by delaying glucose transport across the intestinal barrier. The latter has been supported by studies in rats where naringenin, the aglycone of narirutin from orange juice, inhibited glucose transport across the intestine ${ }^{(10)}$ and in vitro where polyphenols from strawberries $^{(11)}$, apples ${ }^{(11)}$, pomegranate ${ }^{(8)}$, olives ${ }^{(12)}$ and chamomile ${ }^{(13)}$ attenuated the transport of glucose across an intestinal Caco-2 cell monolayer as a model of the small intestine. Orange juice contains glucose, sucrose and fructose but has a lower glycaemic index than expected (50 (SD 4) relative to glucose) when compared to many foods with comparable levels of sugars ${ }^{(14)}$. Both oranges and orange juice are very high in the polyphenol hesperidin (Fig. 1), a flavanone that consists of hesperetin linked to glucose and rhamnose moieties ${ }^{(15)}$. We tested whether the presence of hesperidin could attenuate the glycaemic response of

Abbreviation: DMSO, dimethyl sulfoxide.

* Corresponding author: Dr A. Kerimi, email a.kerimi@leeds.ac.uk 
orange juice employing a combination of in vitro mechanistic studies and interventions in healthy volunteers.

\section{Methods \\ Materials}

All chemicals were purchased from Sigma-Aldrich unless stated otherwise. Magnesium sulphate was from VWR International. Transwell plates with polycarbonate inserts ( 6 well, $0.4 \mu \mathrm{m}$ pore size), tissue culture flasks and filter system $(500 \mathrm{ml}, 0 \cdot 2 \mu \mathrm{m}$ nylon membrane) were from Corning (Appleton Woods). D- $\left[{ }^{14} \mathrm{C}(\mathrm{U})\right]-$ glucose was from Perkin Elmer, $\mathrm{D}-\left[{ }^{14} \mathrm{C}(\mathrm{U})\right]$-fructose was from Hartmann Analytic, and D-fructose, D-glucose and Glutamax were from Thermo Fisher Scientific. Gold Star scintillation cocktail was from Meridian Biotechnologies. Concentrated frozen orange juice ( $4 \times$ concentrate) was from Florida Department of Citrus, USA, and termed orange juice 1. Princes long life $100 \%$ smooth orange juice was from Costco and termed orange juice 2 . Hesperidin (micronised 2S hesperidin) used in the intervention

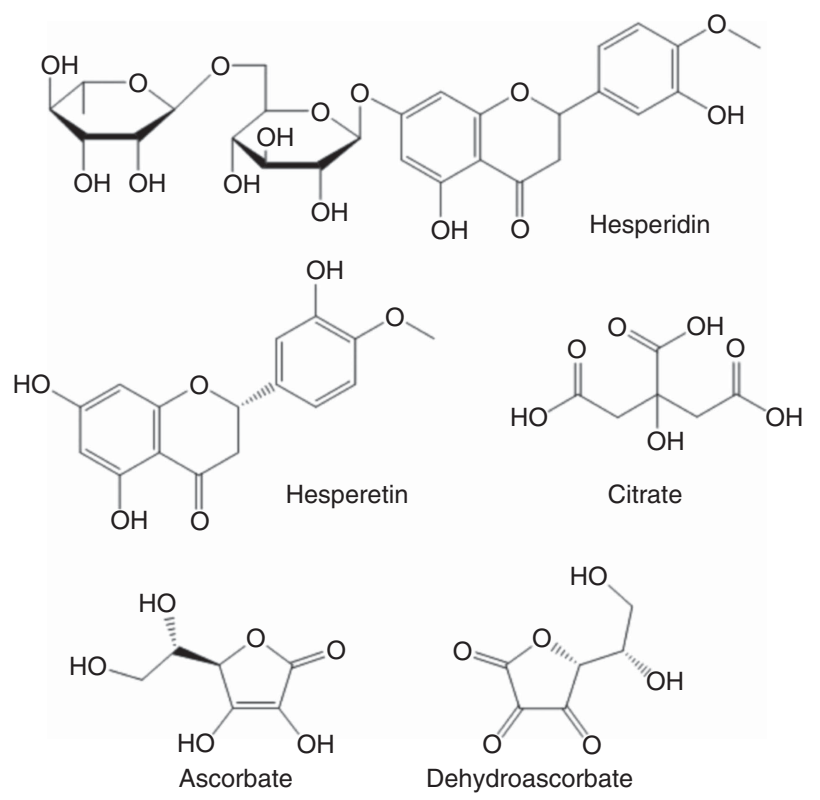

Fig. 1. Chemical structures of tested compounds found in orange juice. studies was from Ferrer HealthTech (www.ferrer.com/ferrerhealthtech). For the intervention study, glucose and fructose were from Holland \& Barrett, sucrose was from Tate and Lyle from a local supermarket, citric acid was from Minerals-Water, malic acid was from Bartek Ingredients Inc., and ascorbic acid was from NutriBiotic. Sodium bicarbonate, used to adjust the $\mathrm{pH}$ of the control solution to the same $\mathrm{pH}$ as the orange juice, was from HealthLeads (healthleadsuk.com).

\section{Preparation of orange juice and its constituents for in vitro experiments}

Orange juice from concentrate (stored in frozen form) was centrifuged ( $2400 \mathrm{~g}, 30 \mathrm{~min}$ ) and one part from the supernatant was diluted with Milli-Q water (to make regular strength orange juice). The $\mathrm{pH}$ was adjusted to $7 \cdot 4$ by the addition of $\mathrm{NaOH} 1 \mathrm{~m}$ and the final dilution of orange juice and water was 1:3. For tests with 10-fold diluted samples, the regular strength orange juice was further diluted with transport buffer (HEPES, $20 \mathrm{~mm}$; $\mathrm{NaCl}, 137 \mathrm{~mm}$; KCl, $4.7 \mathrm{~mm} ; \mathrm{CaCl}_{2}, 1.8 \mathrm{~mm}$ and $\mathrm{MgSO}_{4}, 1.2 \mathrm{~mm}$; adjusted to $\mathrm{pH} 7.4$ using $\mathrm{NaOH}, 1 \mathrm{~m}$ ) and the $\mathrm{pH}$ re-adjusted to 7.4. Glucose, fructose and sucrose were dissolved directly in transport buffer. Stock solutions of hesperidin were prepared in dimethyl sulfoxide (DMSO) and added to the transport buffer containing sugars or to the 'regular strength' orange juice and used immediately or after further dilution. The final concentration of DMSO in transport buffer was $0 \cdot 1 \%$.

\section{Analysis of orange juice and its constituents}

The analysis of the juice given to volunteers is shown in Table 1 ('orange juice 2'). It is different to that used for the in vitro studies ('orange juice 1'). Analysis of sugars ${ }^{(16)}$ and hesperidin ${ }^{(17)}$ in 'orange juice 1' was performed by HPLC, and analysis of ascorbic acid, dehydroascorbic acid and citric acid were performed by capillary electrophoresis ${ }^{(18)}$. Ascorbic acid content of 'orange juice 2' was determined by titration with 2,6dichlorophenol indophenol against a standard curve of ascorbic acid. Malic, citric acid and sugars were analysed as previously described $^{(12)}$.

The content of hesperidin in 'orange juice 2' and in solubility studies was determined by HPLC on an Agilent 1200

Table 1. Composition of the orange juice (Mean values and standard deviations)

\begin{tabular}{|c|c|c|c|}
\hline \multirow[b]{2}{*}{ Compound } & Orange juice 1 (normal strength) for in vitro studies & \multicolumn{2}{|c|}{ Orange juice 2 for intervention studies } \\
\hline & Concentration (mм) & Mean & SD \\
\hline Glucose & 120 & 197 & 14 \\
\hline Fructose & 134 & 138 & 9 \\
\hline Sucrose & 132 & 151 & 20 \\
\hline Citric acid & 31 & 2.72 & 0.21 \\
\hline Ascorbic acid & $2 \cdot 2$ & 1.9 & \\
\hline Dehydroascorbic acid & $0 \cdot 13$ & \multicolumn{2}{|c|}{ ND } \\
\hline Malic acid & ND & 1.04 & 0.08 \\
\hline Hesperidin & 0.79 & 0.168 & 0.003 \\
\hline $\mathrm{pH}$ & & 3.64 & \\
\hline
\end{tabular}

ND, not determined. 
series system (Agilent Technologies). Samples were filtered using 0.45 and $0.2 \mu \mathrm{m}$ pore size syringe filters and $5 \mu \mathrm{l}$ were injected on a ZORBAX Eclipse Plus C18 column $(2 \cdot 1 \times 11 \mathrm{~mm})$ and maintained at $30^{\circ} \mathrm{C}$, at a flow rate of $0.3 \mathrm{ml} / \mathrm{min}$. The solvents used were Milli-Q water/formic acid (95:5; v/v, mobile phase A) and acetonitrile-Milli-Q water-formic acid (90:9:1; v/v, mobile phase B). Separation was achieved by a gradient starting at $5 \% \mathrm{~B}$, reaching $95 \% \mathrm{~B}$ at $20 \mathrm{~min}$, kept at $95 \% \mathrm{~B}$ for $10 \mathrm{~min}$ before returning to baseline. Triplicate analyses were performed for each sample and the absorbance was monitored at 260, 280, 320 and $360 \mathrm{~nm}$. A standard curve was run between 0.005 and $0.1 \mathrm{~mm}$ hesperidin with $r^{2} 0.999$ and retention time of 8.34 (SD 0.03) min ( $n$ 44). Orange juice samples were diluted with water as appropriate to fit the hesperidin concentration onto the standard curve (typically 1:10). To test solubility, hesperidin dissolved in DMSO ( $490 \mathrm{mg}$ in $0.5 \mathrm{ml}$ ) was added to 'orange juice 2' (final concentration of $490 \mathrm{mg}$ hesperidin/l, that is, an additional $0.80 \mathrm{~mm}$ ). The concentration of hesperidin was measured by HPLC and was 0.987 (SD 0.032) $\mathrm{mm}$ (predicted value $0.968 \mathrm{~mm}$, if $100 \%$ hesperidin was in solution after DMSO addition). This shows that hesperidin in DMSO when added to orange juice for in vitro experiments is apparently soluble as assessed by centrifugation, at least up to $0.8 \mathrm{~mm}$.

\section{Culture of Caco-2/TC7 cell monolayers for sugar transport studies}

Caco-2/TC7 cells ${ }^{(19)}$ were kindly provided by Dr M. Rousset (INSERM, U170). Cells $\left(1.2 \times 10^{6}\right)$ were seeded on $75 \mathrm{~cm}^{2}$ cell culture flasks and maintained as described before ${ }^{(12)}$. For glucose transport studies, cells were seeded on 6- or 12-well transwell plates at a density of $6 \times 10^{4}$ cells $/ \mathrm{cm}^{2}$. The cells were allowed to grow and differentiate up to $22 \mathrm{~d}$ in complete medium in the apical and basolateral side, while the apical side was deprived of fetal bovine serum after $7 \mathrm{~d}$.

\section{Measurements of glucose and fructose transport across} Caco-2/TC7 cell monolayers

Differentiated Caco-2/TC7 cell monolayers were used to study the effect of orange juice on glucose transport, from the apical to the basolateral side. On or after $22 \mathrm{~d}$, permeability studies were initiated by careful aspiration of the culture medium from apical and basal compartments, and transport buffer A (HEPES, $20 \mathrm{~mm}$; $\mathrm{NaCl}, 137 \mathrm{~mm}$; KCl, $4.7 \mathrm{~mm} ; \mathrm{CaCl}_{2}, 1.8 \mathrm{~mm}$ and $\mathrm{MgSO}_{4}$, $1.2 \mathrm{~mm}$; adjusted to $\mathrm{pH} 7.4$ using $\mathrm{NaOH}, 1 \mathrm{~m}$ ) was added to each compartment to carefully wash cells. After washing, the solutions were removed and fresh transport buffer A was added into each compartment. Dishes were incubated at $37^{\circ} \mathrm{C}\left(10 \% \mathrm{CO}_{2}\right)$ for $30 \mathrm{~min}$ to allow equilibration of tight junction integrity. Transepithelial electrical resistance measurements were recorded using a Millicell ERS volt-ohm meter fitted with a chopstick probe (Millipore Ltd). The liquid was aspirated and the relevant test solution at $\mathrm{pH} 7.4$ was mixed with $0 \cdot 1 \mu \mathrm{Ci} / \mathrm{ml} \mathrm{D-}\left[\mathrm{U}_{-}{ }^{14} \mathrm{C}\right]-$ glucose or $\mathrm{D}_{-}\left[\mathrm{U}-{ }^{14} \mathrm{C}\right]$-fructose and added apically. All basal solutions consisted of transport buffer at $\mathrm{pH} 7 \cdot 4$. Plates were incubated for $30 \mathrm{~min}$, and the solutions were removed. Apical and basal compartments were washed twice with transport buffer to remove any residual D- $\left[\mathrm{U}_{-}{ }^{14} \mathrm{C}\right]$ glucose or fructose from the cell monolayer or compartment walls and the aliquots were collected. Radiochemical detection of the D-[U- $\left.{ }^{14} \mathrm{C}\right]$-label was performed by combining $5 \mathrm{ml}$ of scintillation cocktail with the apical solutions or the basal solutions and the apical and basal wash solutions. All samples were analysed using a Packard Liquid Scintillation Analyser 1600TR. An aliquot of each test solution was also used to construct an independent standard curve to assess the transport of glucose across to the basolateral side and corrected for any solution matrix effects on radioactive counting.

\section{Inhibition of human GLUT2 and GLUT5 expressed in Xenopus laevis oocytes}

Expression of transporters in Xenopus laevis oocytes and inhibition experiments were conducted as described previously ${ }^{(12)}$. Briefly, after microinjection with mRNA or water as control, oocytes were incubated in $100 \mu \mathrm{m} 0.5 \mu \mathrm{Ci} / \mathrm{ml} \mathrm{D}-\left[{ }^{14} \mathrm{C}(\mathrm{U})\right]$-glucose (GLUT2) or D- $\left[{ }^{14} \mathrm{C}(\mathrm{U})\right]$-fructose (GLUT2 and GLUT5). Incubations were for $5 \mathrm{~min}$ at $25^{\circ} \mathrm{C}$. To terminate the incubation, oocytes (three per reaction) were washed with ice cold $100 \mu \mathrm{m}$ sugar solution and homogenised in $0.3 \mathrm{~m}$ sucrose containing $10 \mathrm{~mm}$ sodium phosphate and a protease inhibitor mixture. After centrifugation at $48000 \mathrm{~g}$ for $1 \mathrm{~h}$ at $4^{\circ} \mathrm{C}$, supernatant was added to a vial containing $5 \mathrm{ml}$ of scintillation fluid and radioactivity was measured using a Packard Tri-Carb 1900 TR Liquid Scintillation Counter.

\section{Assay for sucrase activity}

Inhibition of rat sucrase activity was carried out using a rat intestinal protein extract with sucrose as substrate as described previously ${ }^{(20)}$. Briefly, the assay consisted of substrate $(200 \mu \mathrm{l}$ of sucrose), sodium phosphate buffer $(50 \mu \mathrm{l}, 10 \mathrm{~mm})$, inhibitor or extra buffer $(50 \mu \mathrm{l})$, and the reaction started by adding $200 \mu \mathrm{l}$ of acetone-derived protein extract of rat intestine $(20 \mathrm{mg} \mathrm{solid} / \mathrm{ml})$. After incubation at $37^{\circ} \mathrm{C}$ for $20 \mathrm{~min}$, the reaction was stopped by placing the tubes in a water bath at $100^{\circ} \mathrm{C}$ for $10 \mathrm{~min}$, cooling to room temperature, polyphenols removed by solid phase extraction and the resulting solution analysed for glucose at $340 \mathrm{~nm}$ in a plate reader using hexokinase. Inhibition was calculated as a percentage of the control.

\section{Intervention studies on healthy volunteers}

All intervention studies were approved by the University of Leeds, Faculties of Mathematics and Physical Sciences and Engineering Ethics Committee and were registered at clinicaltrials.gov (NCT03522896). The three independent studies were conducted between September 2017 and May 2018 and are shown in Fig. 9. The suitability of participants was assessed using a pre-study questionnaire, with inclusion criteria as apparently healthy, aged between 18 and 75 years, not smoking, not diabetic, not pregnant, not lactating and not on longterm prescribed medication, with a fasting blood glucose of 3.9- 
Table 2. Intervention studies conducted on healthy volunteers*

(Mean values and standard deviations)

\begin{tabular}{|c|c|c|c|c|c|c|c|}
\hline \multirow[b]{2}{*}{ Study number } & \multirow[b]{2}{*}{ Control } & \multirow[b]{2}{*}{ Treatment } & \multirow[b]{2}{*}{ Volunteers } & \multicolumn{2}{|c|}{ Age (years) } & \multicolumn{2}{|c|}{ BMI $\left(\mathrm{kg} / \mathrm{m}^{2}\right)$} \\
\hline & & & & Mean & SD & Mean & SD \\
\hline 1 & Drink 1† & $\begin{array}{l}200 \mathrm{ml} \text { orange juice } 2+98 \mathrm{mg} \text { hesperidin } \\
\text { (to make approximately } 1 \mathrm{~mm} \text { hesperidin total) }\end{array}$ & $5 f, 5 m$ & $20 \cdot 5$ & $1 \cdot 8$ & $21 \cdot 7$ & $2 \cdot 2$ \\
\hline 2 & Drink 1 & $\begin{array}{l}200 \mathrm{ml} \text { orange juice } 2+37 \mathrm{mg} \text { hesperidin } \\
\text { (to make approximately } 0.5 \mathrm{~mm} \text { hesperidin total) }\end{array}$ & $7 f, 3 m$ & $21 \cdot 0$ & 1.0 & $20 \cdot 4$ & $2 \cdot 7$ \\
\hline 3 & Drink $2 \ddagger$ & $\begin{array}{l}100 \mathrm{ml} \text { orange juice } 2+100 \mathrm{ml} \text { water }+49 \mathrm{mg} \text { hesperidin } \\
\text { (to make approximately } 0.5 \mathrm{~mm} \text { hesperidin total) }\end{array}$ & $6 f, 4 m$ & $21 \cdot 4$ & 0.7 & $22 \cdot 3$ & $2 \cdot 1$ \\
\hline
\end{tabular}

f, Females; m, males.

* All studies were crossover and controlled, with two visits per volunteer per treatment, and were conducted in parallel with different volunteers in each study.

† Drink 1 contained (all mm): glucose, 197; fructose, 138; sucrose, 151; citric acid, 2.7; malic acid, 1.04; ascorbic acid, 1.9. The treatment contained all of these components at the same concentration.

‡ Drink 2 contained (all mm) glucose, 98; fructose, 69; sucrose, 76; citric acid, 1.35; malic acid, 0.52; ascorbic acid, 0.95. The treatment contained all of these components at the same concentration.

$5.9 \mathrm{~mm}$. All participants provided written informed consent before the study started, and height and weight were recorded at the start of the study. Study beverages were given in a crossover design, in a semi-randomised order based on drawing lots (see below), and each volunteer attended twice for the control and twice for the treatment. Participants consumed their normal diet during the studies, but ate the same evening meal on the day before each visit. Participants were enrolled by J. L., J. W. C. and Ryan Kuipers, and the participants arrived at the School of Food Science and Nutrition, University of Leeds premises at approximately 09.00 hours after overnight fasting for at least $12 \mathrm{~h}$. There were no restrictions on physical activity. Data were anonymised by assigning each participant a code. Study 1 involved orange juice 2 with added hesperidin (98 mg/ $200 \mathrm{ml}$ portion). Study 2 involved orange juice 2 with additional hesperidin $(37 \mathrm{mg} / 200 \mathrm{ml}$ portion). Study 3 was 2 -fold diluted orange juice 2 with added hesperidin $(49 \mathrm{mg} / 200 \mathrm{ml}$ portion). Table 2 gives the full details of the beverage compositions. Semi-randomisation in study 1 was performed for the first and second visits and then the third and fourth visits followed the same pattern. For studies 2 and 3, the first beverage was the test material, followed by the control or test in randomised order. Subjects were randomised where indicated by drawing the names of test materials from a 'hat'. The 'randomisation' described is not truly random since the control was only available after the orange juice for studies 2 and 3, which dictated that the orange juice comprised the beverage for the first visit. Capillary blood samples were obtained by finger prick at 0 min (fasting blood glucose) using an Accu-Chek Aviva glucometer according to the FAO/WHO-approved method ${ }^{(21)}$, and the accuracy has been previously validated ${ }^{(12)}$. Following a finger prick, the second drop of blood was used for the measurement of glucose at the indicated time points $(15,30,45,60$, $75,90,120,150$ and $180 \mathrm{~min})$. The peak glucose concentration $\left(C_{\max }\right)$ was used as the primary outcome, since the power calculation was based on this, and the incremental AUC (IAUC) was also estimated based on the same blood glucose data ${ }^{(22)}$. Full details have been described previously ${ }^{(8)}$. For each study listed, ten volunteers were recruited, and the details of control drinks and treatments are provided in Table 2. No side effects were reported during the study.

\section{Statistics and replicates}

Sample size was determined by designing the trial to have $90 \%$ power to detect a clinical difference of $20 \%$ IAUC between test and reference meals based on a power calculation previously reported by us, with $\alpha=0.05$ and $\beta=0.1^{(23)}$. The CV of peak glucose measurement was $11.9 \%$ based on the calculation given in full in Nyambe ${ }^{(24)}$. With participants being controls of themselves, and each attending twice for each intervention, a minimum of ten participants was required, as calculated and used before ${ }^{(21)}$. The trapezoidal rule was used to calculate the IAUC for each volunteer, and data analysis was performed by the two-tailed paired $t$ test. Comparisons between control and treatment in D-[U- $\left.{ }^{14} \mathrm{C}\right]$-glucose and $\left[\mathrm{U}^{-14} \mathrm{C}\right]$-deoxy-D-glucose uptake cell experiments was carried out by independent samples two-tailed Student's $t$ test between control and treatment, and the two-tailed values were adjusted for multiple comparisons with the Bonferroni correction; data are presented as mean values and standard deviations with a minimum of three independent experiments and six replicate wells/experiment. For $\left[{ }^{14} \mathrm{C}(\mathrm{U})\right]$-glucose and $\left[{ }^{14} \mathrm{C}(\mathrm{U})\right]$-fructose uptake experiments into Xenopus oocytes expressing human GLUT2 and GLUT5, data were normalised against water-injected oocytes for each condition, and the two-tailed independent samples $t$ test was used to assess significance, as reported previously $^{(12)}$.

\section{Results}

Differentiated Caco-2/TC7 monolayers transport $\left[{ }^{14} \mathrm{C}(\mathrm{U})\right]$-glucose from the apical to basolateral compartments and are a commonly used model to study the potential modulators of intestinal absorption of sugars. At $5 \mathrm{~mm}$ apical glucose, the rate of transport was $19 \cdot 3(\mathrm{sD} 3.3) \mathrm{nmol} / \mathrm{min}$, which equates to a transport of $13 \%$ of the applied $\left[{ }^{14} \mathrm{C}(\mathrm{U})\right]$-glucose over the incubation time of $30 \mathrm{~min}$, comparable to our previous data using this system ${ }^{(12)}$. The composition of the orange juice tested in the cell experiments is shown in Table 1, and these values were used to design the transport experiments. Hesperidin alone exhibited significant inhibition when applied at the tested concentrations of 80 and $800 \mu \mathrm{m}$, typical concentrations found in 
orange juice (Table 1). However, the much higher concentration of $1600 \mu \mathrm{m}$ did not show significant inhibition and even slightly enhanced transport (Fig. 2). Since the inhibition appeared more complex than a simple dose-response, and hesperidin in orange juice would normally be contained within the matrix of the juice affecting its solubility ${ }^{(25)}$, we then tested the effects of orange juice, neutralised to the jejunal $\mathrm{pH}$ of $7 \cdot 4$, on the transport of $\left[{ }^{14} \mathrm{C}(\mathrm{U})\right]$-glucose. However, the high glucose concentration of orange juice necessitated increasing the concentration of glucose in the apical compartment in the control experiments, and so to set up the system, we tested the transport of $\left[{ }^{14} \mathrm{C}(\mathrm{U})\right]$-glucose at higher glucose concentrations. Under these conditions, $\left[{ }^{14} \mathrm{C}(\mathrm{U})\right]$-glucose transport was enhanced by the presence of fructose and sucrose, when present at the same concentrations as in orange juice (Fig. 3). Under these conditions, hesperidin attenuated the transport of $\left[{ }^{14} \mathrm{C}(\mathrm{U})\right]$-glucose. Adding extra hesperidin to orange juice did not markedly change the rate of transport of $\left[{ }^{14} \mathrm{C}(\mathrm{U})\right]$-glucose (Fig. 3).

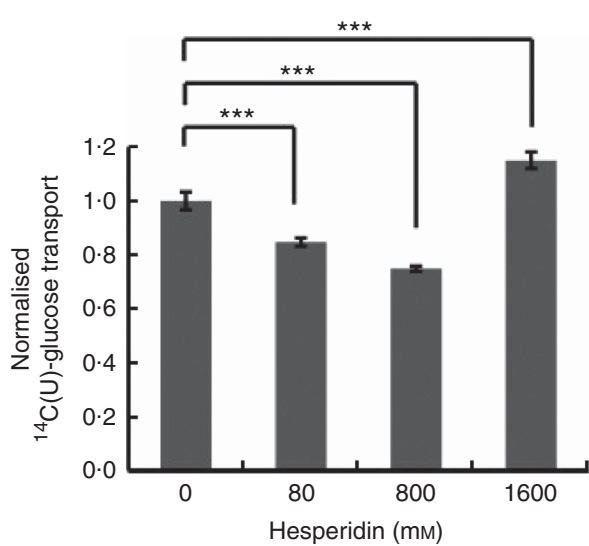

Fig. 2. Effect of hesperidin on glucose transport across differentiated Caco-2/ TC7 cell monolayers. Effect of various concentrations of hesperidin on apical to basolateral transport of $5.5 \mathrm{~mm}\left[{ }^{14} \mathrm{C}(\mathrm{U})\right]$-glucose across differentiated Caco-2/ TC7 cell monolayers. Values are means $(n 6-12)$ with standard deviations represented by vertical bars. ${ }^{\star \star \star} P \leq 0.001$.
After consumption, beverages are diluted with digestive juices such as saliva, stomach secretions, pancreatic juice and small intestinal secretions before reaching the small intestine, but the exact amount of dilution is complex and dependent on many factors and this fact has been known for many years ${ }^{(26)}$. We therefore tested the effects of a more substantially diluted orange juice (10-fold) on transport of $\left[{ }^{14} \mathrm{C}(\mathrm{U})\right]$-glucose. All experiments on 10-fold diluted juice were compared to $12 \mathrm{~mm}$ glucose (the concentration in 10-fold diluted juice) together with $13 \mathrm{~mm}$ fructose and $13 \mathrm{~mm}$ sucrose. Added hesperidin, that is, both when added to the component sugars and to the juice itself, significantly inhibited the transport of $\left[{ }^{14} \mathrm{C}(\mathrm{U})\right]$-glucose (Fig. 4). To determine the relative contribution of sodium-glucose linked transporter 1 (SGLT1) to the transport, Na-free conditions were compared with normal Na-containing transport buffer. The absence of $\mathrm{Na}$ led to an approximately $31 \%(P<0 \cdot 001)$ decrease in the transport of ${ }^{14} \mathrm{C}$-glucose, and the presence of $800 \mu \mathrm{M}$ hesperidin further decreased this by approximately $38 \%$, $P<0 \cdot 001$ (Fig. 5).

We also tested the effect of orange juice and hesperidin on transport of fructose across differentiated Caco-2 cell monolayers. Hesperidin mildly inhibited $\left[{ }^{14} \mathrm{C}(\mathrm{U})\right]$-fructose transport from apical to basolateral compartments, but this inhibitory effect was abolished in the presence of other sugars (Fig. 6(a)). Consistent with this, hesperidin showed a greater inhibition at lower concentration of sugars (Fig. 6(b)). To examine the mechanisms further, we tested the effect of hesperidin on $\left[{ }^{14} \mathrm{C}\right.$ (U)]-glucose transport into $X$. laevis oocytes expressing human GLUT2. Hesperidin inhibited GLUT2 but the effect was modest (Fig. 7(a)). On the other hand, the aglycone hesperetin was a much more potent inhibitor (Fig. 7(b)). In contrast, hesperidin was a more effective inhibitor of $\left[{ }^{14} \mathrm{C}(\mathrm{U})\right]$-fructose transport by GLUT5 in comparison to hesperetin (Fig. 7(c) and (d)).

The sucrose component of any food or beverage requires prior hydrolysis by the brush border enzyme sucrase before absorption of the component sugars as glucose and fructose via sugar transporters ${ }^{(27)}$. To determine whether hesperidin could affect the digestive hydrolytic step, we determined its effect on rat

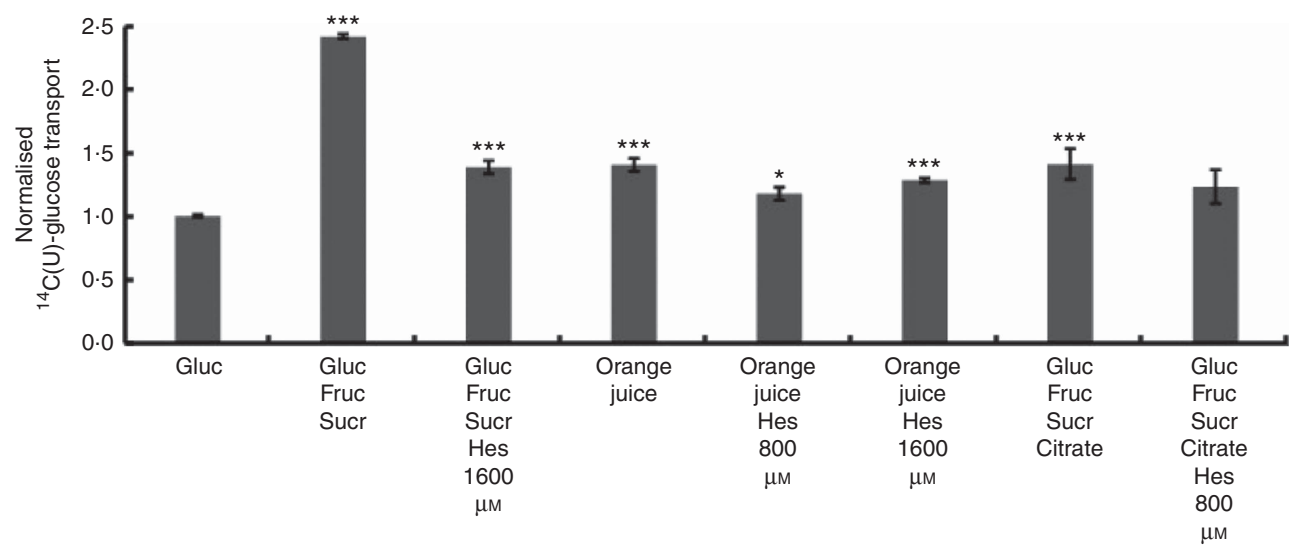

Fig. 3. Effect of orange juice 1 and constituents on glucose transport across differentiated Caco-2/TC7 cell monolayers. Effect of mixtures of components on transport of $\left[{ }^{14} \mathrm{C}(\mathrm{U})\right]$-glucose across differentiated Caco-2/TC7 cell monolayers. All conditions contained $120 \mathrm{~mm}\left[{ }^{14} \mathrm{C}(\mathrm{U})\right]$-glucose. Concentrated orange juice 1 was diluted 4-fold into the cell culture medium and the $\mathrm{pH}$ adjusted to $\mathrm{pH} 7.4$ termed 'regular strength'. When present as indicated, fructose and sucrose were at 130 mm, and citrate was $30 \mathrm{~mm}$, which is according to the concentrations found in the juice (Table 1). Gluc, glucose; Fruc, fructose; Sucr, sucrose; Hes, hesperidin. Values are

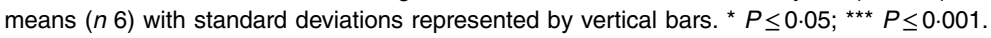




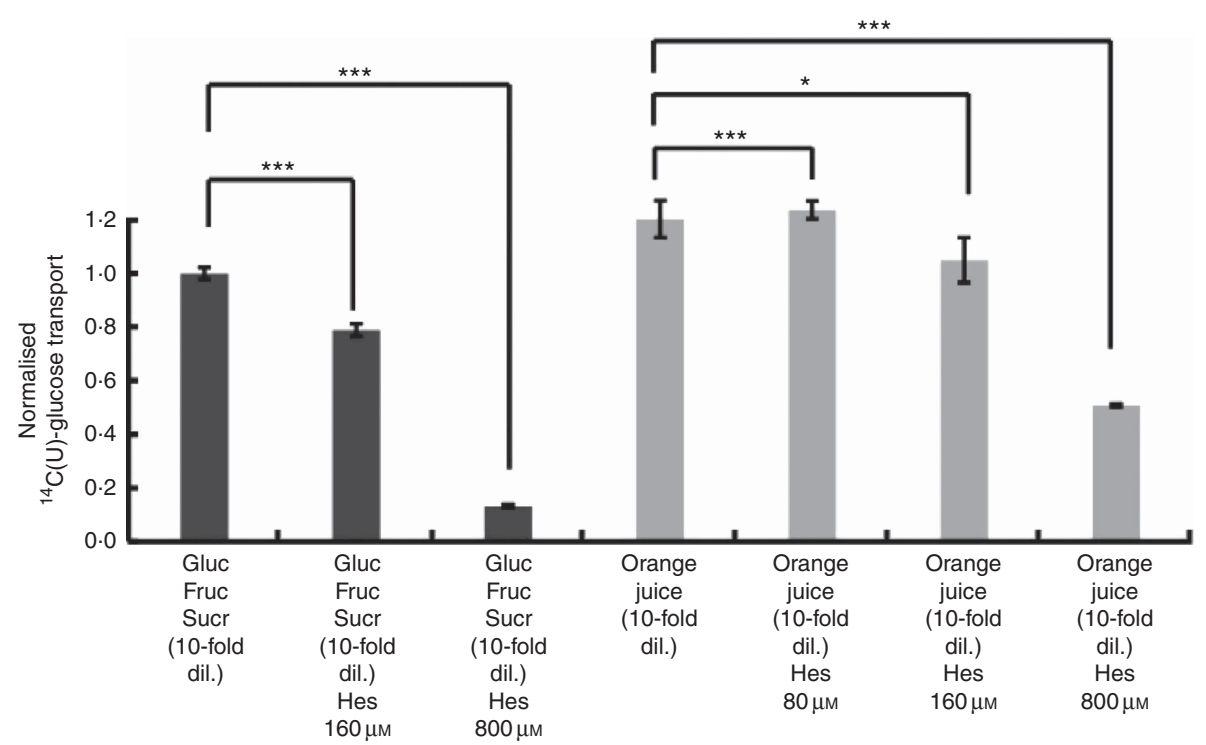

Fig. 4. Effect of diluted orange juice 1 and constituents on glucose transport across differentiated Caco-2/TC7 cell monolayers. All conditions contained $12 \mathrm{~mm}\left[{ }^{14} \mathrm{C}\right.$ (U)]-glucose. Concentrated orange juice 1 was diluted 40 -fold into the cell culture medium and the $\mathrm{pH}$ adjusted to $\mathrm{pH} 7.4$, so that effectively the orange juice was 10-fold diluted from 'regular strength'. When present and indicated, fructose and sucrose were at $13 \mathrm{~mm}$, which is similar to the concentrations found in 10-fold diluted juice; Gluc, glucose; Fruc, fructose; Sucr, sucrose; Hes, hesperidin. Values are means $(n 6)$ with standard deviations represented by vertical bars. ${ }^{*} P \leq 0.05$; ${ }_{\star \star \star *} P \leq 0.001$.

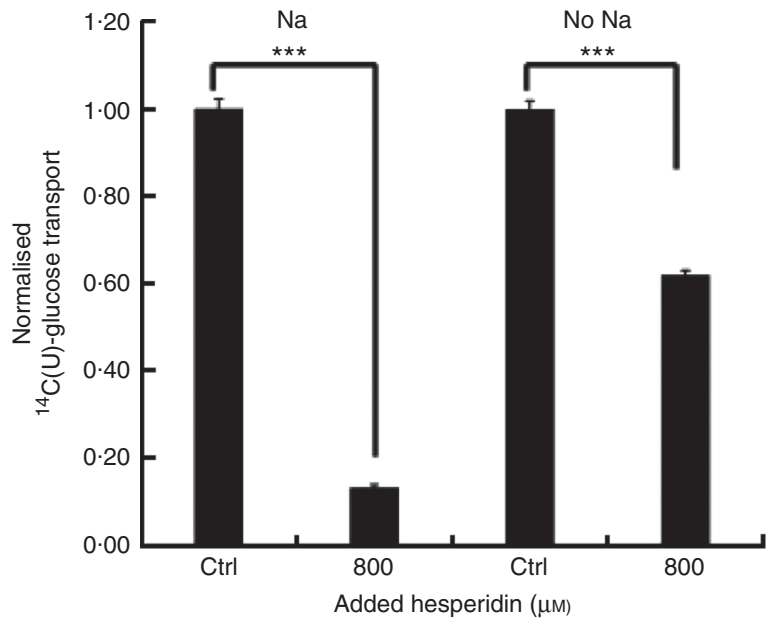

Fig. 5. Effect of hesperidin on glucose transport across differentiated Caco-2/ TC7 cell monolayers in the presence and absence of sodium. Effect of sodiumfree medium and hesperidin on apical to basolateral transport of $12 \mathrm{~mm}\left[{ }^{14} \mathrm{C}(\mathrm{U})\right]$ glucose across differentiated Caco-2/TC7 cell monolayers. Values are means ( $n$ 6) with standard deviations represented by vertical bars. ${ }^{* \star} P \leq 0.001$.

sucrase activity. In contrast to acarbose, which as positive control was an excellent inhibitor, hesperidin even up to $1 \mathrm{~mm}$ did not inhibit sucrase activity (Fig. 8). We can therefore predict that any effects of hesperidin on postprandial glycaemia after orange juice consumption would be through inhibition of GLUT transporters and not attenuation of brush border sucrase activity.

To determine whether the effects observed in vitro on sugar transport were sufficient to elicit an effect in vivo, we conducted three separate human intervention studies on orange juice and measured the postprandial glycaemic response as biomarker for the effect of hesperidin. The analysis of the juice given to volunteers is shown in Table 1 ('orange juice 2'). It is different to that used for the in vitro studies ('orange juice 1'). This is due to Hurricane Irma (Florida, US, August 2017) which resulted in the loss of the stored orange juice at the Florida Department of Citrus, which had been used for the in vitro work, and consequently no further supplies for the intervention studies were available. We therefore used a different commercially available orange juice for consumption by volunteers.

Volunteers consumed orange juice supplemented with two different doses of hesperidin or diluted orange juice with added hesperidin according to the design shown in Table 2 and Fig. 9. The control drink contained glucose, fructose, sucrose, ascorbic acid, citric acid and malic acid at the same concentrations as found in the orange juice. The results are summarised in Fig. 10. The effect on postprandial glycaemia was most pronounced in the case of the diluted orange juice, where there was a highly significant decrease in the peak blood glucose relative to the control drink $\left(\Delta C_{\max }=-0.5 \mathrm{~mm}, P=0.0146\right)$. This decrease was seen in all individuals (Fig. 11), where the change in glucose $C_{\max }$ can be clearly seen from 15 to $30 \mathrm{~min}$. The change in peak blood glucose was also significant for one of the hesperidinsupplemented orange juices, although no significant change in AUC could be observed for all three studies.

\section{Discussion}

Consumption of hesperidin has been shown to affect several health biomarkers in studies on volunteers ${ }^{(28-31)}$. It also attenuated hyperglycaemia in animal models, such as in male $\mathrm{C} 57 \mathrm{BL} / \mathrm{KsJ}-\mathrm{db} / \mathrm{db}$ mice, an animal model for type 2 diabetes ${ }^{(32)}$. However, the effect of hesperidin on glucose absorption and carbohydrate digestion has not been explored. We therefore tested the hypothesis that hesperidin could affect postprandial glycaemia in healthy volunteers and be partially responsible for 
(a)

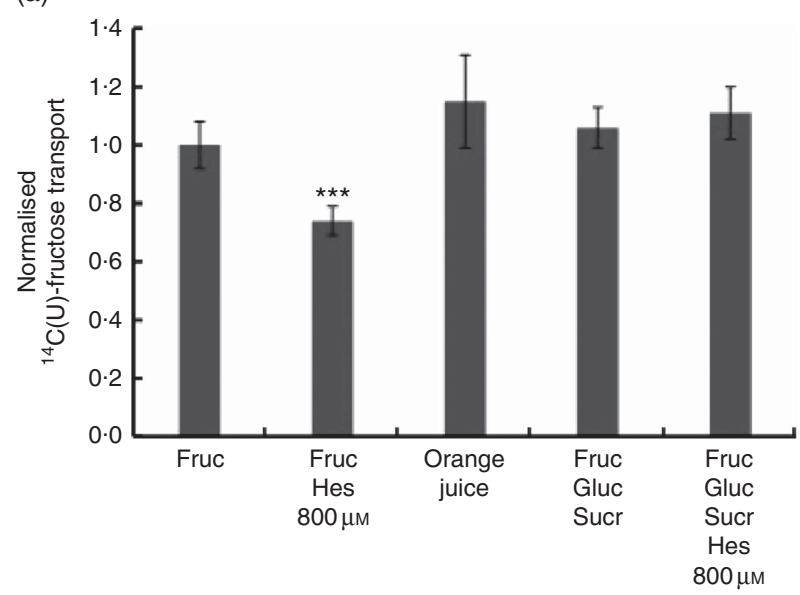

(b)

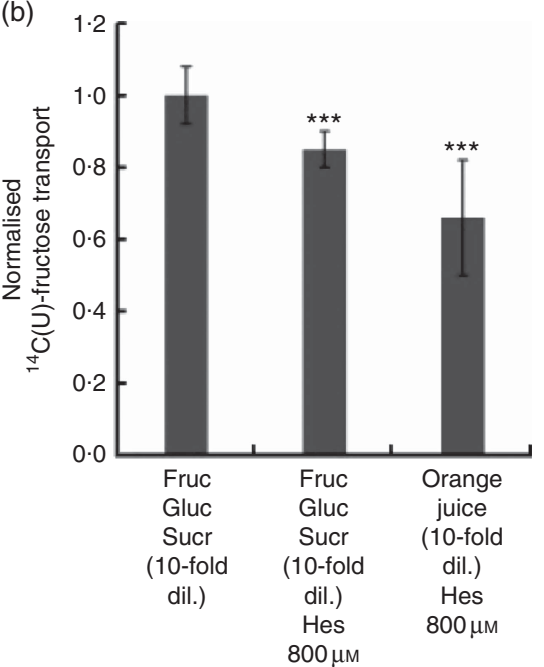

Fig. 6. Effect of orange juice 1 components on $\left[{ }^{14} \mathrm{C}(U)\right]$-fructose transport across differentiated Caco-2/TC7 cell monolayers. (a) When indicated, apical solutions contained $130 \mathrm{~mm} \mathrm{[}{ }^{14} \mathrm{C}(\mathrm{U})$ ]-fructose. Concentrated orange juice 1 was diluted 4-fold into the cell culture medium and the $\mathrm{pH}$ adjusted to $\mathrm{pH} 7 \cdot 4$, so that effectively the orange juice was 'original strength'. When present and indicated, glucose and sucrose were at 120 and $130 \mathrm{~mm}$, respectively. Values are means $(n 12)$ with standard deviations represented by vertical bars. ${ }^{* *} P \leq 0.001$. (b) When indicated, apical solutions contained $13 \mathrm{~mm}\left[{ }^{14} \mathrm{C}(\mathrm{U})\right]$-fructose. Concentrated orange juice 1 was diluted 40-fold into the cell culture medium and the $\mathrm{pH}$ adjusted to $\mathrm{pH} 7.4$, so that effectively the orange juice was 10 -fold diluted. When present and indicated, glucose and sucrose were at 12 and $13 \mathrm{~mm}$, respectively. Gluc, glucose; Fruc, fructose; Sucr, sucrose; Hes, hesperidin. Values are means $(n 12)$ with standard deviations represented by vertical bars. ${ }^{* *} P \leq 0.001$.

(a)

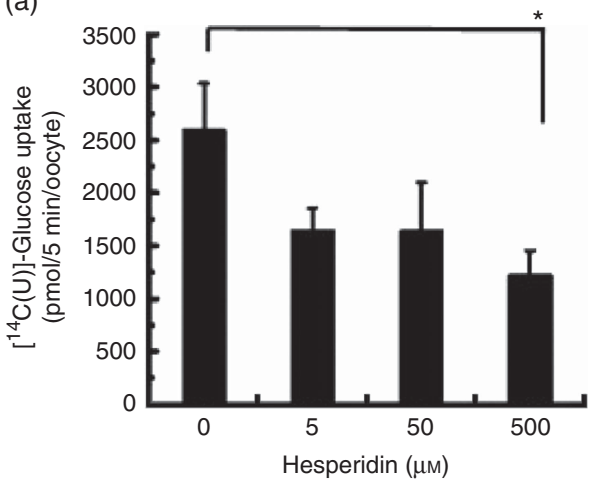

(c)

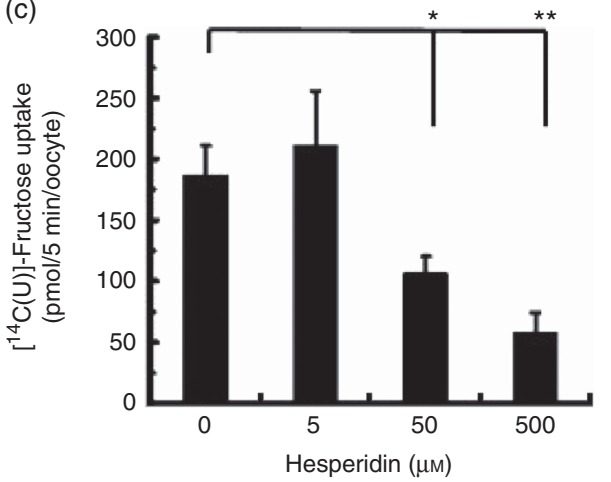

(b)

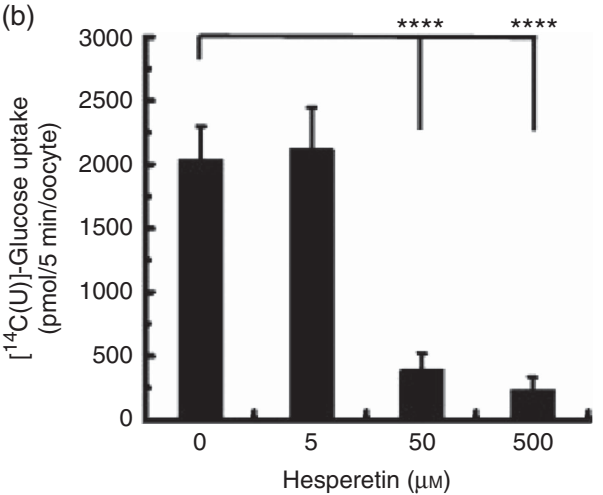

(d)

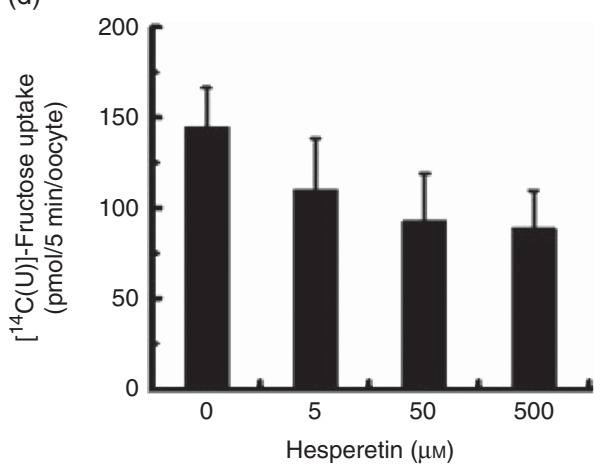

Fig. 7. Effect of hesperidin and hesperetin on GLUT2 and GLUT5 expressed in Xenopus laevis oocytes. Effects of hesperidin (a) or hesperetin (b) on glucose uptake by $X$. laevis oocytes expressing GLUT2. Effects of hesperidin (c) or hesperetin (d) on fructose uptake by $X$. laevis oocytes expressing GLUT5. One (GLUT5) or two (GLUT2) days post-cloned RNA injection, oocytes were incubated with $0.1 \mathrm{~mm}\left[{ }^{14}\right.$-C]-labelled glucose or fructose. After 5 min, the amount of internalised radiolabel was measured by scintillation counting. Each data point represents the means with their standard errors of six (GLUT2) or twelve (GLUT5) replicates. ${ }^{*} P \leq 0.05$; ${ }^{* *} P \leq 0.01$; **** $P \leq 0.0001$. 


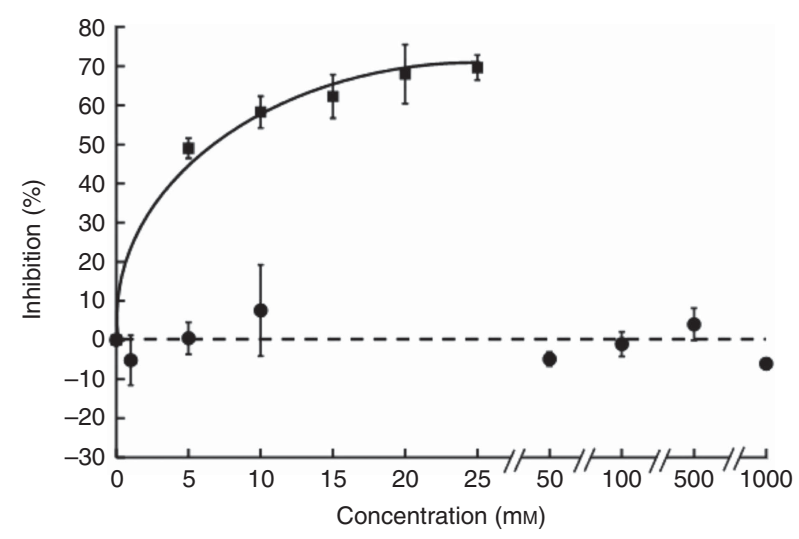

Fig. 8. Effect of hesperidin and acarbose on rat intestinal sucrase activity. Acarbose $(\boldsymbol{\square})$ or hesperidin $(\bullet)$ was added to the assay for rat intestinal sucrase activity. Values are means $(n 3)$ with standard deviations represented by vertical bars. the glycaemic index of orange juice which is lower than predicted based on its sugar content. Hesperidin lowered glucose transport across differentiated Caco-2/TC7 cell monolayers and inhibited GLUT2 and GLUT5 transporters when specifically expressed in $X$. laevis oocytes. Hesperidin, however, did not inhibit rat intestinal sucrase activity. These in vitro data suggest that hesperidin could possibly act to slow down the rate of sugar absorption in vivo. While testing orange juice on healthy volunteers, we found that the postprandial glycaemic response was blunted under certain conditions as assessed by the peak blood glucose concentration relative to a control drink containing the constituent sugars, organic acids and vitamin C. In comparison, change in AUC did not reach significance (Fig. 10). These data imply that the hesperidin or other non-nutrient components of orange juice could be acting to slow down the glucose absorption step through partial inhibition of intestinal sugar transport, which would lead to lowered maximum glucose blood glucose concentration but result in no change in the total sugar absorbed,

(a)

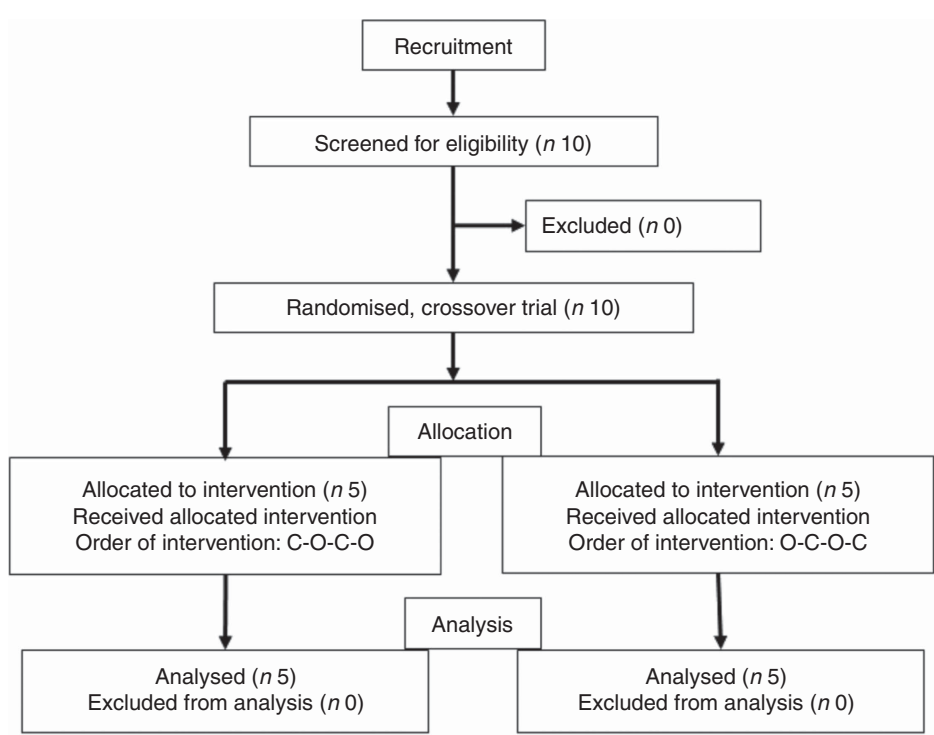

(b)

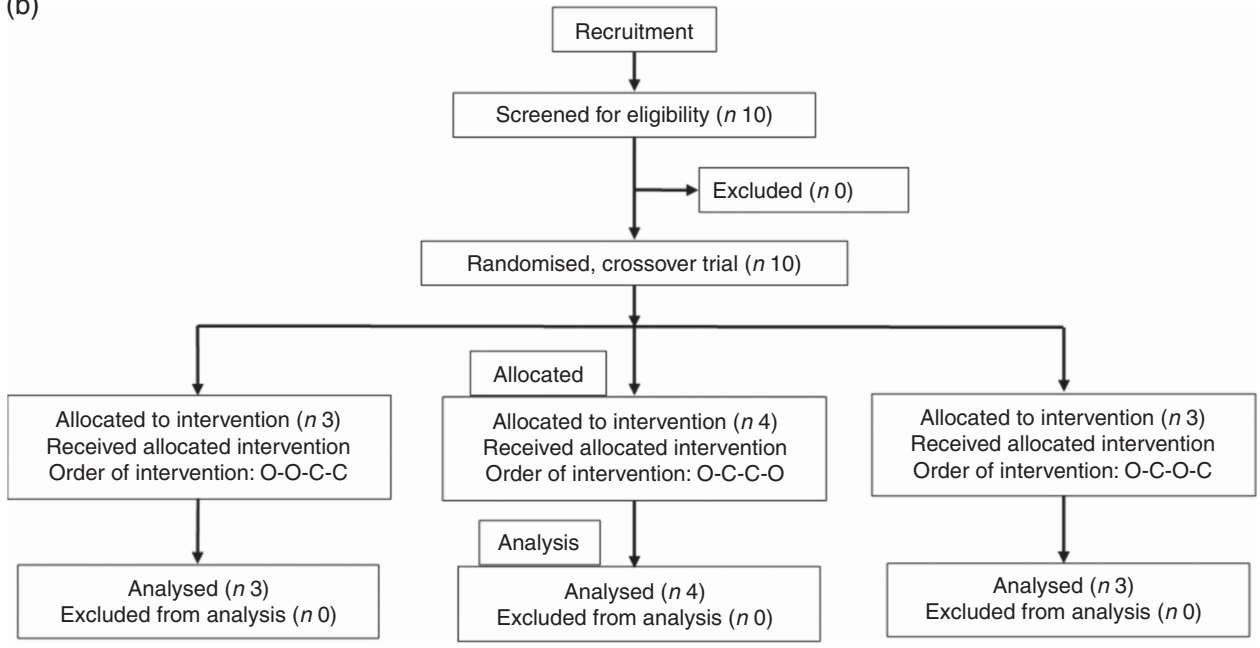

Fig. 9. Participant flow diagrams for the interventions. (a) Design of study 1. (b) Design of studies 2 and 3. O, orange juice; C, control. 
(a)

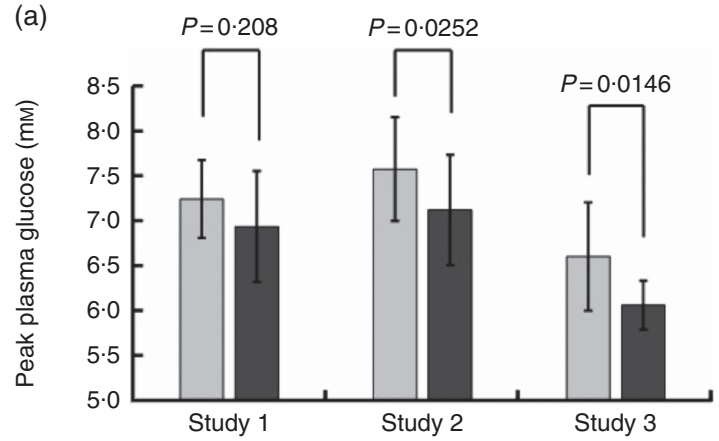

(b)
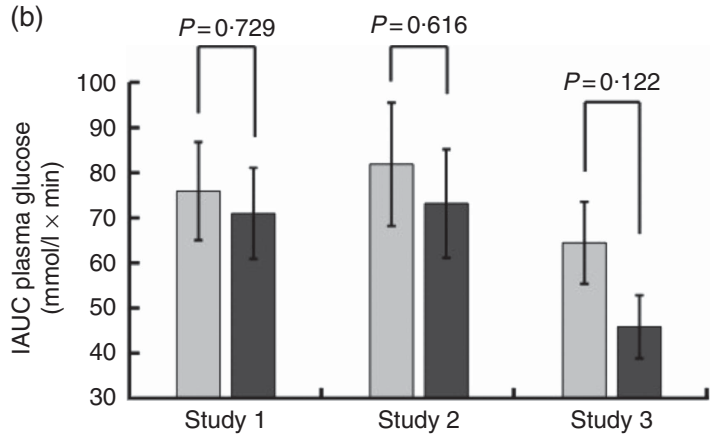

Fig. 10. Summary of effect of orange juice on postprandial glycaemic response. Study 1 was orange juice 2 with added hesperidin $(98 \mathrm{mg} / 200 \mathrm{ml}$ portion). Study 2 was orange juice 2 with additional added hesperidin (37 mg/ $200 \mathrm{ml}$ portion). Study 3 was 2 -fold diluted orange juice 2 with added hesperidin ( $49 \mathrm{mg} / 200 \mathrm{ml}$ portion). See Table 2 for full details of the beverages. Postprandial glucose concentration was measured in ten volunteers relative to a control drink containing equivalent amounts of sucrose, glucose, fructose, citric acid and ascorbic acid, and the mean values with standard deviations presented. Each volunteer attended twice for the control and twice for the orange juice, with a postprandial blood collection period of $180 \mathrm{~min}$. The volunteers in studies 1, 2 and 3 were different.

since the absorption can occur along the length of the intestine and would therefore be shifted to a later time.

The solubility of hesperidin is complex, and this can influence results obtained in vitro. Hesperidin is soluble in pure water up to $50 \mu \mathrm{m}^{(33)}$, although we have found that it is much more soluble, at least transiently for the timescale of an experiment, when dissolved first in DMSO and then introduced into an aqueous milieu. In orange juice, it is present at up to millimolar concentrations, and higher concentrations have been previously used in intervention studies on hesperidin-enriched orange juice ${ }^{(34)}$. The solubility of hesperidin is also modified when present in the orange juice matrix; and although the exact location and form of hesperidin is not known, it is clearly heterogeneous as some techniques such as centrifugation or filtering remove only a proportion of the hesperidin ${ }^{(34)}$. In commercially available orange juices, the distribution of hesperidin between 'soluble' and 'insoluble' fractions was variable depending on processing. After orange juice consumption, hesperidin stays in the small intestine without being digested or modified, until it reaches the colon.

We ascribe the changes in the intervention studies to partial inhibition of intestinal GLUT by hesperidin and not to the inhibition of digestive brush border enzymes such as sucrase. We clearly show that hesperidin does not inhibit rat sucrase activity (an $\alpha$-glucosidase-type activity), even when present in solution at $1 \mathrm{~mm}$. The aglycone, hesperetin, inhibited $\alpha$-glucosidase from Saccharomyces cerevisiae with $\mathrm{IC}_{50}=0.38$ (sD $0.05) \mathrm{mm}^{(35)}$, but this is a yeast enzyme with very little sequence homology to mammalian enzymes, and hence it is not relevant to human or animal nutrition. In addition, hesperetin in the aglycone form is at extremely low levels in orange juice. We have unpublished results ( $\mathrm{G}$ Williamson, unpublished results) to show that hesperidin does not inhibit human $\alpha$-amylase activity, and so it is unlikely that hesperidin in orange juice would inhibit the digestion of starch if consumed with a starchy food such as bread.

We have previously shown that polyphenol-rich apple and strawberry extracts ${ }^{(11)}$, a multi-plant supplement ${ }^{(36)}$, a chamomile extract $^{(13)}$, and oleuropein from olives ${ }^{(12)}$ inhibited ${ }^{14} \mathrm{C}$-glucose transport across the differentiated Caco- 2 cell model. The mechanism is due to the inhibition of specific sugar transporters. Here we show that hesperetin was a more potent inhibitor of GLUT2 than hesperidin, which is comparable with the greater effect of quercetin aglycone, but not rutin, on inhibition of GLUT2 expressed in Xenopus oocytes ${ }^{(37,38)}$. Further the aglycone of naringenin but not the glycoside inhibited glucose uptake in rabbit and rat intestine in vitro ${ }^{(10)}$. However, it is notable that hesperidin, but not the aglycone hesperetin, inhibited the uptake of fructose by GLUT5 expressed in X. laevis oocytes, and this could account for some of the mild attenuation of fructose transport across Caco-2/TC7 cell monolayers. Hesperetin-7-[2$O$-( $\alpha$-L-rhamnopyranosyl)- $\beta$-D-glucopyranoside] (neohesperidin) inhibited the uptake of ${ }^{3} \mathrm{H}$-glucose ( $1 \mathrm{~mm}$ ) into Caco-2 cells by approximately $50 \%$, but the cells were not on permeable filters and so apical to basolateral transport was not examined. In Na-free conditions, the inhibition of uptake by neohesperidin was abolished, implying that neohesperidin interacted with SGLT1 ${ }^{(39)}$. Hesperetin also inhibited glucose uptake in breast cancer cells by down-regulation of GLUT1 and inhibited insulin-induced GLUT4 translocation ${ }^{(40)}$. A related polyphenol, homoeriodictyol, increased glucose uptake in Caco-2 cells via an SGLT-1-meditated pathway ${ }^{(41)}$. Since only the hesperetin component of hesperidin is absorbed, and not the intact hesperidin itself, the treatment of nongut cells is not relevant to human nutrition and though hesperidin protected retinal ganglial RGC-5 cells from highglucose-induced stress ${ }^{(42)}$, this is unlikely to occur in vivo.

The main limitation of the study is that the participants and the investigators were not blinded to the interventions, owing to the nature of the food. The study was also not truly randomised, though we think that it is unlikely that a single postprandial intervention would change the response to the next intervention several days later. Identical orange juice was used for the three intervention studies, but it was different to that used for the in vitro studies, and further, the method of analysis of the juices used for the in vitro work was different to that used for the intervention studies. There were no reported side effect or harm, as the treatments were well within the parameters of food as normally consumed. Despite any limitations, we can conclude that, in summary, the presence of hesperidin in orange juice slows down absorption of glucose in the intestine, owing mainly to the effects on the GLUT2 transporter. This is sufficient to blunt the maximum postprandial glucose concentration and increases the time required for total glucose absorption especially when the 

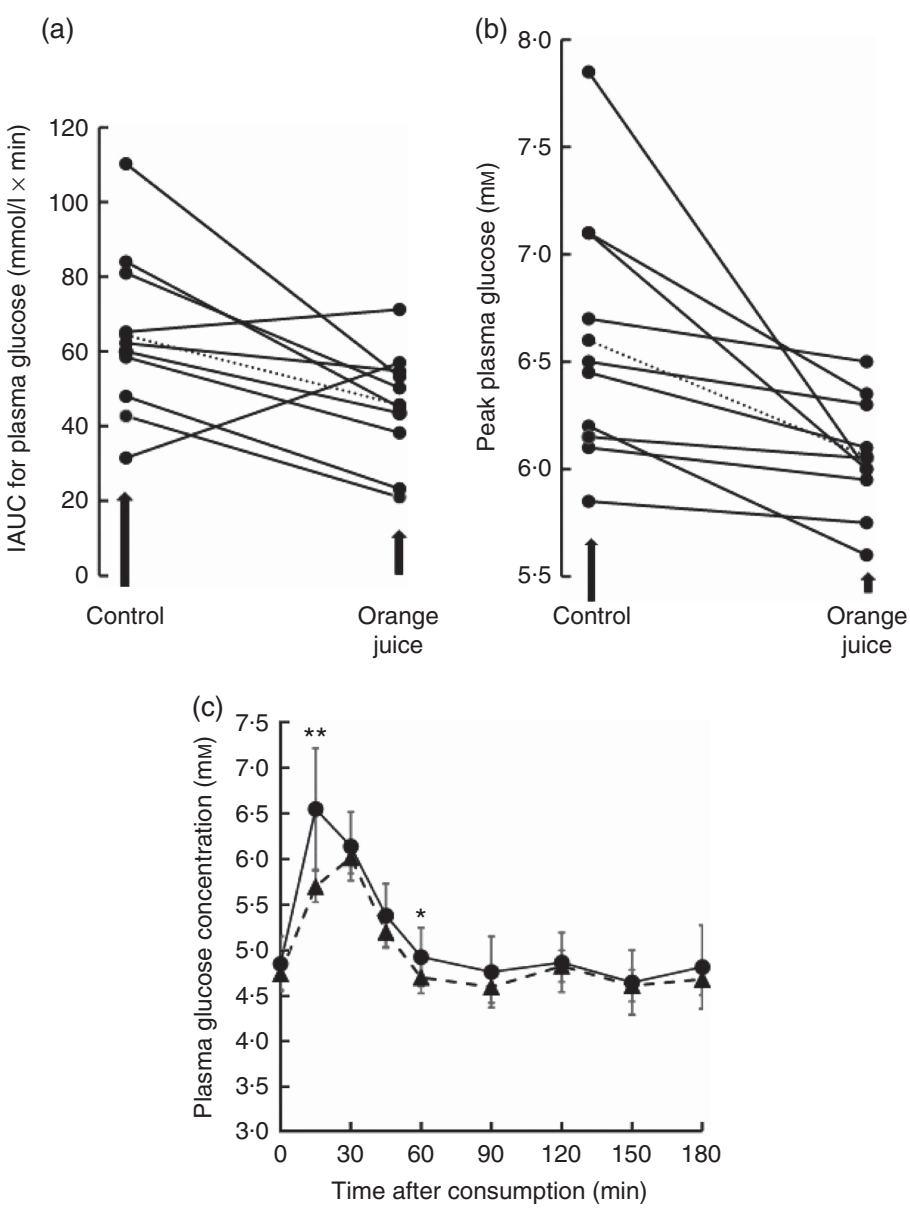

Fig. 11. Effect of 2-fold diluted orange juice 2 on postprandial glycaemic response. Orange juice 2 was consumed by volunteers and compared to a control drink containing the equivalent amount of sucrose, glucose, fructose, citric acid, malic acid and ascorbic acid. This is labelled as drink 2 in Table 2 . Postprandial glucose was measured and the incremental AUC (iAUC, a) or peak plasma glucose (b) estimated for each individual over 180 min. The mean value is shown by a dotted line. (c) The postprandial blood glucose concentration measured in all volunteers in response to consumption of orange juice ( $)$ or control drink ( $\mathbf{A})$ is shown as mean values with standard deviations. ${ }^{*} P \leq 0.05 ;{ }^{* *} P \leq 0.01$.

orange juice is diluted, without significantly modifying the total amount of sugar absorbed in healthy volunteers.

\section{Acknowledgements}

The authors thank the Florida Department of Citrus, an executive agency of the Florida government, USA, for funding part of this work. The authors also thank the volunteers and also Mr Ryan Kuipers for help with the human intervention studies.

Planning of research, analysis of data, writing paper, cell transport experiments, analysis of organic acids and sugars of 'orange juice 2': A. K. Oocyte experiments: J. S. G. Hesperidin analysis, sucrase assays: S. C. Human intervention studies: J. W. C., J. L. Analysis of 'orange juice 1', planning research, provision of materials: P. F. C., R. W. Planning of research, analysis of data, writing paper: G. W.

R. W. and P. F. C. are, or were, employed by the Florida Department of Citrus, an executive agency of Florida tasked with the promotion, protection and regulation of the Florida Citrus industry based in Bartow, Florida. The work reported here was partially funded by the Florida Department of Citrus.
G. W. has received funding from Nestlé, and conducted consultancy for Nutrilite, USA, and Suntory, UK. The other authors report no conflict of interest.

\section{References}

1. Livesey G, Taylor R, Hulshof T, et al. (2008) Glycemic response and health - a systematic review and meta-analysis: relations between dietary glycemic properties and health outcomes. Am J Clin Nutr 87, 258S-268S.

2. Ludwig DS, Hu FB, Tappy L, et al. (2018) Dietary carbohydrates: role of quality and quantity in chronic disease. BMJ 361, k2340.

3. Jenkins DJ, Wolever TM, Taylor RH, et al. (1981) Glycemic index of foods: a physiological basis for carbohydrate exchange. Am J Clin Nutr 34, 362-366.

4. Marsh K, Barclay A, Colagiuri S, et al. (2011) Glycemic index and glycemic load of carbohydrates in the diabetes diet. Curr Diab Rep 11, 120-127.

5. Johnston KL, Clifford MN \& Morgan LM (2003) Coffee acutely modifies gastrointestinal hormone secretion and glucose tolerance in humans: glycemic effects of chlorogenic acid and caffeine. Am J Clin Nutr 78, 728-733.

6. Tsuneki H, Ishizuka M, Terasawa M, et al. (2004) Effect of green tea on blood glucose levels and serum proteomic 
patterns in diabetic $(\mathrm{db} / \mathrm{db})$ mice and on glucose metabolism in healthy humans. BMC Pharmacol 4, 18.

7. Torronen R, Kolehmainen M, Sarkkinen E, et al. (2013) Berries reduce postprandial insulin responses to wheat and rye breads in healthy women. J Nutr 143, 430-436.

8. Kerimi A, Nyambe-Silavwe H, Gauer JS, et al. (2017) Pomegranate juice, but not an extract, confers a lower glycemic response on a high-glycemic index food: randomized, crossover, controlled trials in healthy subjects. Am J Clin Nutr 106, 1384-1393.

9. Shimabukuro M, Higa N, Chinen I, et al. (2006) Effects of a single administration of acarbose on postprandial glucose excursion and endothelial dysfunction in type 2 diabetic patients: a randomized crossover study. J Clin Endocrinol Metab 91, 837-842.

10. Li JM, Che CT, Lau CB, et al. (2006) Inhibition of intestinal and renal $\mathrm{Na}+$-glucose cotransporter by naringenin. Int J Biochem Cell Biol 38, 985-995.

11. Manzano S \& Williamson G (2010) Polyphenols and phenolic acids from strawberry and apple decrease glucose uptake and transport by human intestinal Caco-2 cells. Mol Nutr Food Res 54, 1773-1780.

12. Kerimi A, Nyambe-Silavwe H, Pyner A, et al. (2018) Nutritional implications of olives and sugar: attenuation of post-prandial glucose spikes in healthy volunteers by inhibition of sucrose hydrolysis and glucose transport by oleuropein. Eur J Nutr (epublication ahead of print version 8 March 2018).

13. Villa-Rodriguez JA, Aydin E, Gauer JS, et al. (2017) Green and chamomile teas, but not acarbose, attenuate glucose and fructose transport via inhibition of GLUT2 and GLUT5. Mol Nutr Food Res 61, 1700566.

14. Foster-Powell K, Holt SH \& Brand-Miller JC (2002) International table of glycemic index and glycemic load values: 2002. Am J Clin Nutr 76, 5-56.

15. Neveu V, Perez-Jimenez J, Vos F, et al. (2010) PhenolExplorer: an online comprehensive database on polyphenol contents in foods. Database (Oxford) 2010, bap024.

16. White DR \& Cancalon PF (1992) Detection of beet sugar adulteration of orange juice by liquid-chromatography pulsed amperometric detection with column switching. J AOAC Int 75, 584-587.

17. Anonymous (2005) Determination of hesperidin and naringin by HPLC. Int Fed Fruit Juice Prod 58, 1-6.

18. Cancalon PF (2001) Routine analysis of ascorbic acid in citrus juice using capillary electrophoresis. J AOAC Int 84, 987-991.

19. Zucco F, Batto AF, Bises G, et al. (2005) An inter-laboratory study to evaluate the effects of medium composition on the differentiation and barrier function of Caco-2 cell lines. Altern Lab Anim 33, 603-618.

20. Pyner A, Nyambe-Silavwe H \& Williamson G (2017) Inhibition of human and rat sucrase and maltase activities to assess antiglycemic potential: optimization of the assay using acarbose and polyphenols. J Agric Food Chem 65, 8643-8651.

21. Brouns F, Bjorck I, Frayn KN, et al. (2005) Glycaemic index methodology. Nutr Res Rev 18, 145-171.

22. Wolever TMS (2006) Glycaemic index: a physiological classification of dietary carbohydrate. Glycaemic Index: A Physiological Classification of Dietary Carbohydrate, pp. 1-227. Wallingford, UK: CABI Publishing.

23. Nyambe-Silavwe H \& Williamson G (2016) Polyphenol- and fibre-rich dried fruits with green tea attenuate starch-derived postprandial blood glucose and insulin: a randomised, controlled, single-blind, cross-over intervention. Br J Nutr 116, 443-450.

24. Nyambe H (2016) Effects of carbohydrase inhibiting polyphenols on glycaemic response in vivo. PhD Thesis, University of Leeds.
25. Gil-Izquierdo A, Gil MI, Tomas-Barberan FA, et al. (2003) Influence of industrial processing on orange juice flavanone solubility and transformation to chalcones under gastrointestinal conditions. J Agric Food Chem 51, 3024-3028.

26. Hendrix TR \& Bayless TM (1970) Digestion: intestinal secretion. Annu Rev Physiol 32, 139-164.

27. Kishi K, Tanaka T, Igawa M, et al. (1999) Sucrase-isomaltase and hexose transporter gene expressions are coordinately enhanced by dietary fructose in rat jejunum. J Nutr 129, 953-956.

28. Homayouni F, Haidari F, Hedayati M, et al. (2017) Hesperidin supplementation alleviates oxidative DNA damage and lipid peroxidation in type 2 diabetes: a randomized double-blind placebo-controlled clinical trial. Phytother Res 31, 1539-1545.

29. Haidari F, Heybar H, Jalali MT, et al. (2015) Hesperidin supplementation modulates inflammatory responses following myocardial infarction. J Am Coll Nutr 34, 205-211.

30. Kean RJ, Lamport DJ, Dodd GF, et al. (2015) Chronic consumption of flavanone-rich orange juice is associated with cognitive benefits: an 8-wk, randomized, double-blind, placebo-controlled trial in healthy older adults. Am J Clin Nutr 101, 506-514.

31. Morand C, Dubray C, Milenkovic D, et al. (2011) Hesperidin contributes to the vascular protective effects of orange juice: a randomized crossover study in healthy volunteers. Am J Clin Nutr 93, 73-80.

32. Jung UJ, Lee MK, Jeong KS, et al. (2004) The hypoglycemic effects of hesperidin and naringin are partly mediated by hepatic glucose-regulating enzymes in $\mathrm{C} 57 \mathrm{BL} / \mathrm{KsJ}-\mathrm{db} /$ db mice. J Nutr 134, 2499-2503.

33. Tommasini S, Calabro ML, Stancanelli R, et al. (2005) The inclusion complexes of hesperetin and its 7-rhamnoglucoside with (2-hydroxypropyl)-beta-cyclodextrin. J Pharm Biomed Anal 39, 572-580.

34. Vallejo F, Larrosa M, Escudero E, et al. (2010) Concentration and solubility of flavanones in orange beverages affect their bioavailability in humans. J Agric Food Chem 58, 6516-6524.

35. Gong Y, Qin XY, Zhai YY, et al. (2017) Inhibitory effect of hesperetin on alpha-glucosidase: molecular dynamics simulation integrating inhibition kinetics. Int J Biol Macromol 101, 32-39.

36. Farrell TL, Ellam SL, Forrelli T, et al. (2013) Attenuation of glucose transport across Caco-2 cell monolayers by a polyphenol-rich herbal extract: interactions with SGLT1 and GLUT2 transporters. Biofactors 39, 448-456.

37. Song J, Kwon O, Chen S, et al. (2002) Flavonoid inhibition of sodium-dependent vitamin C transporter 1 (SVCT1) and glucose transporter isoform 2 (GLUT2), intestinal transporters for vitamin C and Glucose. J Biol Chem 277, 15252-15260.

38. Kwon O, Eck P, Chen S, et al. (2007) Inhibition of the intestinal glucose transporter GLUT2 by flavonoids. FASEB $J$ 21, 366-377.

39. Johnston K, Sharp P, Clifford M, et al. (2005) Dietary polyphenols decrease glucose uptake by human intestinal Caco2 cells. FEBS Lett 579, 1653-1657.

40. Yang Y, Wolfram J, Boom K, et al. (2013) Hesperetin impairs glucose uptake and inhibits proliferation of breast cancer cells. Cell Biochem Funct 31, 374-379.

41. Lieder B, Hoi JK, Holik AK, et al. (2017) The flavanone homoeriodictyol increases SGLT-1-mediated glucose uptake but decreases serotonin release in differentiated Caco-2 cells. PLOS ONE 12, e0171580.

42. Liu WY, Liou SS, Hong TY, et al. (2017) Protective effects of hesperidin (citrus flavonone) on high glucose induced oxidative stress and apoptosis in a cellular model for diabetic retinopathy. Nutrients $\mathbf{9}, 1312$. 